\title{
Procesos de centralización urbana: factores individuales y tipologías metropolitanas
}

\author{
José Manuel Torrado \\ Ricardo Duque-Calvache \\ Isabel Palomares-Linares \\ Universidad de Granada. Departamento de Sociología \\ josetr@ugr.es \\ ricardoduque@ugr.es \\ ipalomares@ugr.es
}

Recibido: octubre de 2018

Aceptado: febrero de 2019

Publicado: julio de 2020

\section{Resumen}

La vuelta a la ciudad constituye un fenómeno de gran interés. Algunos individuos y hogares buscan la centralidad, pese a que la tendencia general continúa siendo la expansión hacia lo suburbano. Nuestra aportación consiste en conectar los planteamientos de los estudios sobre comportamiento residencial con las explicaciones de la recuperación de los municipios centrales para valorar hasta qué punto las teorías explican la realidad de las ciudades metropolitanas españolas. Para ello, hemos empleado datos del censo de población de 2011 y modelos de regresión logística binaria. Nuestros datos confirman la capacidad explicativa de las variables descritas en la literatura, pero al mismo tiempo muestran un cierto sesgo: funcionan mejor en las áreas de gran tamaño que en las menores. No se trata de una mera cuestión de escala, sino de que las primeras están atravesando una fase de recentralización, en tanto que en las segundas encontramos un proceso de concentración.

Palabras clave: recentralización; ciudades centrales; áreas metropolitanas; movilidad residencial; desarrollo metropolitano 


\section{Resum. Processos de centralització urbana: factors individuals $i$ tipologies metropolitanes}

El retorn a la ciutat constitueix un fenomen de gran interès. Alguns individus i llars busquen la centralitat, tot i que la tendència general continua sent l'expansió a espais suburbans. La nostra aportació consisteix a connectar els plantejaments dels estudis sobre comportament residencial amb les explicacions de la recuperació dels municipis centrals per valorar fins a quin punt les teories expliquen la realitat de les ciutats metropolitanes espanyoles. Per tal de comprovar-ho, hem emprat dades del cens de població de 2011 i models de regressió logística binària. Les nostres dades confirmen la capacitat explicativa de les variables descrites en la literatura, però al mateix temps mostren un cert biaix: funcionen millor en les àrees de grans dimensions que en les petites. No es tracta d'una mera qüestió d'escala, sinó que les primeres estan travessant una fase de recentralització, mentre que en les segones hi trobem un procés de concentració.

Paraules clau: recentralització; ciutats centrals; àrees metropolitanes; mobilitat residencial; desenvolupament metropolità

Résumé. Processus de centralisation urbaine : facteurs individuels et typologies métropolitaines

Le retour en ville constitue un phénomène de grand intérêt. Certains individus et ménages recherchent la centralité, bien que la tendance générale reste l'expansion vers les banlieues. Notre contribution consiste à relier les approches des études sur le comportement résidentiel aux explications de la reprise des communes centrales afin d'évaluer dans quelle mesure les théories expliquent la réalité des métropoles espagnoles. Pour cela, nous avons utilisé les données du recensement de la population de 2011 et des modèles de régression logistique binaire. Nos données confirment la capacité explicative des variables décrites dans la littérature, mais montrent en même temps un certain biais : elles fonctionnent mieux dans les grandes zones que dans les plus petites. Ce n'est pas une simple question d'échelle. C'est plutôt que les premiers traversent une phase de recentralisation, tandis que dans les petites agglomérations, on constate un processus de concentration.

Mots-clés: recentralisation; villes centrales; zones métropolitaines; mobilité résidentielle; développement métropolitain

\section{Abstract. Processes of urban centralization: Individual factors and metropolitan typologies}

The return to the city constitutes a phenomenon of great interest. Some individuals and households seek centrality, although the general trend continues to be suburbanization. Our contribution aims to relate studies on residential behavior to those addressing the recovery of the central urban districts in order to ascertain whether these theories correctly explain the reality of Spanish metropolitan cities. Data were taken from the 2011 population census and binary logistic regression models were the main method used. Our models confirm the explanatory capacity of the variables described in the literature, but at the same time reveal a certain bias: they work better in large areas than in smaller areas. It is not a mere question of scale, but rather the former are going through a recentralization phase, while the latter are in a process of concentration.

Keywords: recentralization; central cities; metropolitan areas; residential mobility; metropolitan development 


\section{Sumario}

\begin{tabular}{|c|c|}
\hline 1. Introducción & $\begin{array}{l}\text { 5. Los movimientos de centralización } \\
\text { y el ciclo de expansión metropolitano }\end{array}$ \\
\hline 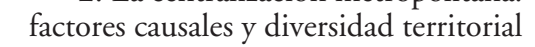 & 6. Conclusiones \\
\hline 3. Metodología & Referencias bibliográficas \\
\hline $\begin{array}{r}\text { Modelización de la movilidad hacia los } \\
\text { municipios centrales }\end{array}$ & $\begin{array}{l}\text { Anexo. Clasificación de áreas siguie } \\
\text { la tipología de Feria (2013) }\end{array}$ \\
\hline
\end{tabular}

\section{Introducción}

Durante cientos de años las ciudades han crecido de manera continuada tanto en población como en superficie, merced a un éxodo rural masivo y al crecimiento natural de la población. Las urbes fagocitan los municipios circundantes y dan lugar a las grandes áreas metropolitanas. Las salidas desde la ciudad central empujan los límites de lo urbano, en un proceso de creciente suburbanización. Sin embargo, estos movimientos centrífugos son numéricamente hegemónicos, pero no los únicos que operan sobre la estructura urbana. Al perder población por los cambios con destino a las coronas, los municipios centrales se abren a la posibilidad de nuevas entradas. Muchas van a ser protagonizadas por inmigrantes (interiores y, sobre todo, internacionales), pero una parte relevante van a ser habitantes de otras zonas de la ciudad, que cambian su vida suburbana a cambio de las posibilidades que ofrece el centro de la ciudad. En los últimos años, son muchos los autores que constatan un incremento de la centralización en las grandes ciudades españolas, como Madrid, Barcelona, Valencia, Bilbao o Sevilla (Feria y Andújar, 2015; López-Gay, 2014; Pujadas et al., 2012), e incluso en otras de menor tamaño, como Granada (Susino y Palomares-Linares, 2013).

No obstante, pese a este renovado papel de las cabeceras metropolitanas y al incremento de las dinámicas centrípetas, la mayoría de los estudios realizados en torno a estos cambios suelen tener un foco muy concreto en dos sentidos. En el ámbito mediático y académico, hay un enorme interés por los procesos de gentrificación (Criekingen, 2010; Duque-Calvache, 2016), es decir, por el análisis de procesos de vuelta al centro que suponen un choque y un desplazamiento de los antiguos habitantes, y que suelen focalizarse en barrios concretos. Por otro lado, la mayor parte de los estudios han tendido a centrarse en ciudades con procesos metropolitanos consolidados. Sabemos bastante acerca de grandes ciudades como Madrid, Barcelona, París o Toronto, pero bastante menos sobre urbes de menor entidad en las cuales estos procesos son también relevantes. Esto ha llevado a que, si bien la centralización ha sido descrita y estudiada, no se conozca su diversidad territorial (Champion, 2001). Pretendemos superar esas dos limitaciones habituales con el estudio del fenómeno de la centralización en términos agregados, en la ciudad al completo y en todas las ciudades de un país, de manera que obtengamos una imagen conjunta del 
proceso más allá de sus manifestaciones concretas. Al mismo tiempo, nos interesa que esta visión no oculte la realidad de las ciudades de menor tamaño, por lo que dedicaremos nuestra atención también a estudiar si el proceso adopta formas diferentes en las ciudades según sus dimensiones.

Nuestro punto de partida es considerar que no todos los flujos de centralización son iguales ni constituyen una "vuelta al centro». En las etapas tempranas del desarrollo urbano, se pueden considerar más bien movimientos de concentración de población hacia grandes municipios. Posteriormente, la dispersión de esa población concentrada posibilita la suburbanización y la creación de dinámicas complejas metropolitanas. En las etapas de desarrollo más tardías, estos movimientos repuntan de manera considerable, especialmente en las áreas más desarrolladas (las regiones urbanas como Madrid o Barcelona, pero también áreas metropolitanas como Sevilla o Bilbao), pero con un cariz diferente a la concentración originaria, de modo que se constituyen en dinámicas de recentralización (Susino, Duque-Calvache, 2012), ya que se trata de movimientos que revierten una tendencia a la suburbanización, en tanto que en la concentración no hay este trasfondo previo. En este caso, sí hay una vuelta al centro: son en muchos casos antiguos habitantes del núcleo central que se trasladaron a la corona que retornan. Para algunos autores, este tipo de dinámica marca una nueva etapa en la evolución urbana (López-Gay, 2017), y en cualquier caso refuerza la consolidación del área como mercado unificado de vivienda.

Nuestros objetivos son conocer los factores individuales y agregados que explican la centralización, para poner a prueba las teorías que la explican desde una perspectiva individual, es decir, como acción de individuos y hogares, al tiempo que introducimos también las características del área metropolitana como factor explicativo. Estudios previos han demostrado que las conductas residenciales no solamente se explican por factores micro, sino que el contexto en que estas acciones se producen es también un elemento clave que orienta las conductas de los hogares (Duque-Calvache et al., 2017). En un segundo momento, analizaremos la validez del modelo explicativo general a las diversas áreas según su grado de desarrollo metropolitano, y reproduciremos este modelo explicativo en dos tipos de áreas diferentes, las áreas más consolidadas (regiones urbanas y grandes áreas) y las nacientes (áreas menores e incipientes). Así, intentamos evaluar si los modelos explicativos funcionan de manera similar en ciudades en las que dominan las dinámicas de recentralización y en otras en las que existen dinámicas de concentración. Partiendo de estos objetivos y de las aportaciones de la literatura, podemos enunciar dos hipótesis:

a) La centralización es una conducta residencial que se explica tanto por rasgos del individuo y el hogar como por variables agregadas metropolitanas.

b) Las variables y explicaciones empleadas para analizar los movimientos de centralización son más adecuadas para entender los procesos en grandes urbes (recentralización) que en aquellas de menor tamaño (concentración). 
Para contrastarlas, revisaremos las aportaciones realizadas por la literatura que permiten analizar la centralización en función de la elección residencial de individuos y hogares, así como aquellas que hacen hincapié en su diversidad territorial. En un segundo momento, expondremos la fuente empleada, el censo de 2011, y la técnica utilizada, la regresión logística. En tercer lugar, abordamos objetivos e hipótesis a través del análisis de los resultados obtenidos. Nuestras conclusiones nos confirman la existencia de factores agregados que modulan y alteran la influencia de las variables individuales y de hogar en los procesos de centralización. Además, se ha comprobado que las variables empleadas habitualmente explican mejor el cambio en las grandes ciudades que en aquellas de menor tamaño.

\section{La centralización metropolitana: factores causales y diversidad territorial}

Ciertos procesos de cambio general favorecen que los actores sociales y económicos vuelvan a mirar hacia las cabeceras metropolitanas tras la fase expansiva, que suele denominarse suburbanización. Entre estos procesos, encontramos cambios de naturaleza sociodemográfica, como el vaciamiento por envejecimiento de las cabeceras (Galiana y Vinuesa, 2012), que ayuda a la liberación de espacio residencial en las mismas, o la segunda transición demográfica y los cambios en el comportamiento residencial que conllevan (Buzar et al., 2005). De este modo, se ha generado una nueva preferencia por lo urbano denso con la idea de desarrollar ciertos estilos de vida basados en la proximidad (Pablos y Sánchez-Tovar, 2003). También operan procesos de naturaleza económica, relacionados con el auge de una nueva economía de aglomeración, pero esta vez de servicios y conocimiento en lugar de medios industriales (Storper y Manville, 2006), que encuentra en las ciudades centrales su hábitat idóneo. Estos procesos de cambio confluyen en un renovado papel de las cabeceras en el conjunto de las áreas metropolitanas, que está dando lugar a procesos de transformación socioespacial, tales como la gentrificación (Criekingen, 2010), en los cuales los movimientos de centralización cobran cada vez más un papel relevante (López-Gay y Recaño, 2008; Torrado, 2018).

Podemos dividir las aportaciones realizadas respecto a la centralización en dos grandes bloques, que corresponden, a su vez, a los dos objetivos de este trabajo. De un lado, un cuerpo de trabajos relativamente amplio que trata sobre los factores individuales que llevan a los individuos a elegir la localización de su vivienda. Se trata de un conjunto de trabajos heterogéneo y muy amplio, pero entre ellos solo encontramos un puñado que específicamente tratan la centralización como movimiento residencial (López-Gay y Recaño, 2008; Turcotte y Vézina, 2010; Marois y Bélanger, 2013, entre otros). De otro lado, tenemos la literatura sobre la estructura y la dinámica de las áreas metropolitanas, más centrada en los flujos agregados que en las decisiones de hogar. Por otra parte, en estos trabajos se estudia el papel que tienen estos movimientos en las distintas etapas del proceso de metropolización, y se señala que este movimiento asume una naturaleza distinta según la etapa en la que las áreas concretas se encuen- 
tren. Si las consecuencias de estos desplazamientos evolucionan a medida que la ciudad se transforma, es de lógica asumir también que los factores individuales que llevan a las personas a centralizarse pueden cambiar, y que también vayan variando los perfiles de sus protagonistas (Torrado, 2017).

\subsection{Factores individuales de la elección residencial de las cabeceras}

Si entendemos la centralización como resultado de una elección entre residir en la cabecera o en la corona, hemos de responder a dos preguntas: ¿qué diferencia a las cabeceras de la opción suburbana?, ¿qué lleva a los individuos a optar por cada una de ellas? Respecto a la primera pregunta, la literatura sobre la elección residencial de espacios tiende a entender que cabeceras y coronas, más allá de las particularidades locales que puedan existir, son espacios residenciales diferenciados (Gober y Behr, 1982; Pisman et al., 2011).

En el caso español, las cabeceras metropolitanas concentran la mayoría de las instituciones educativas superiores (especialmente universidades), así como las actividades económicas y los trabajos que requieren una mayor cualificación. También hay una fuerte concentración de actividades comerciales y de ocio de carácter cultural (teatros, museos, cines, etcétera) y servicios personales. Es decir, que residir en la cabecera permite disponer de las ventajas de la centralidad administrativa, funcional, económica, sanitaria... Pero al trasladar nuestro foco a la vivienda, encontramos un parque residencial de las cabeceras caracterizado, en general, por contener viviendas antiguas, más pequeñas y con una mayor presencia del alquiler (Andújar et al., 2015). Es importante destacar que, a diferencia de otros países, el municipio central en las ciudades españolas no es un mero CBD ampliado, es también un espacio residencial, con densidad variable en función de las ciudades, pero generalmente compacto. Por su parte, las coronas metropolitanas no son zonas suburbanas con funciones exclusivamente residenciales (típicas en cierto urbanismo anglosajón), aunque sí predomina este uso. En su parque de viviendas, se encuentran unidades de mayor tamaño, de construcción reciente y más frecuentemente en propiedad. Estas características diferenciales de cabeceras y coronas llevan a que los individuos opten por unas u otras según cuatro factores fundamentales: los acontecimientos ligados al curso vital, la posición social, los estilos de vida y la experiencia residencial previa.

Al hablar del curso vital nos referimos a ciertos eventos, cambios familiares y laborales que ocurren a lo largo de la vida de los individuos y que desencadenan cambios en las necesidades y preferencias residenciales (Coulter et al., 2016). La literatura que ha tratado la elección residencial de las ciudades centrales tiende a entender que ciertos cambios favorecen que las personas opten por las cabeceras metropolitanas: la salida del hogar familiar, con frecuencia ligada al acceso a la formación superior o al primer empleo (Marois y Bélanger, 2013; Turcotte y Vézina, 2010); la formación y ruptura — por divorcio o separación- de la pareja (Feijten y Ham, 2007), o la entrada en la etapa de nido vacío (Nguyen, 2006). Todos estos hechos son susceptibles de modelar nuestras decisiones de movilidad. 
No obstante, la mayoría de los estudios al respecto en España no cuentan con datos longitudinales que permitan contrastar el efecto concreto del evento. Esta limitación se intenta paliar empleando los datos transversales disponibles, operacionalizando las fases del curso vital a través de variables demográficas como la edad o la estructura del hogar. Estos estudios resaltan la mayor presencia en la centralización de las parejas sin hijos, los hogares unipersonales y los hogares no familiares (Ford y Champion, 2000; López-Gay y Recaño, 2008; Duque-Calvache, 2015), y algunos también destacan los hogares monoparentales (Buzar et al., 2005; 2007). Respecto a la edad, no hay una posición clara. Si bien algunos sostienen que la centralización la protagonizan personas jóvenes (Marois y Bélanger, 2013), hay estudios de signo contrario (Duque-Calvache, 2015) y otros que incluso afirman que no influye (South y Crowder, 1997; Sanchez y Dawkins, 2001).

La posición social, por su parte, es una cuestión más controvertida. Los estudios norteamericanos describen con frecuencia unas ciudades centrales habitadas por personas de bajos ingresos (Nelson y Edwards, 1993), receptores de asistencia social y minorías étnicas (South y Crowder, 1997). En el caso europeo (y también español), ocurre justo al contrario, se considera el centro un espacio valioso y deseable. De modo que existen correlaciones positivas entre la posición que se ocupa en la estructura social y la probabilidad de elegir las ciudades centrales como espacio residencial. Los protagonistas de estos movimientos son las personas con estatus ocupacional elevado y estudios superiores (López-Gay y Recaño, 2008; Duque-Calvache, 2015).

Estas diferencias pueden vincularse con la propia genealogía histórica de las ciudades norteamericanas y europeas (Ullán de la Rosa, 2014). La evolución de las ciudades norteamericanas se caracterizó por una suburbanización generalizada de la población blanca y adinerada, relegando a las minorías pobres a los guetos de las cabeceras. En las ciudades europeas este proceso no fue tan radical, por la menor diferenciación étnica de la población y, principalmente, porque los mejor situados en la estructura social nunca abandonaron del todo los espacios centrales. Así, en la medida en que cabeceras y coronas se vinculan a uno y otro lado del Atlántico a grupos sociales distintos, la elección social de unas y otras también lo hace. No obstante, esta es una realidad cada vez más cambiante, a causa de los potentes procesos de gentrificación que desde los años 80 se vienen dando en algunas de las principales metrópolis mundiales (Ley, 1996).

Por otro lado, el estilo de vida también es citado como una variable fundamental que explica la preferencia por las cabeceras. Si bien es un concepto polisémico (Mahmud et al., 2012), en términos de elección residencial hay cierto consenso en entenderlo como un conjunto de actitudes y prácticas respecto al trabajo, la familia, la interacción social y el uso del espacio. La literatura acerca de los estilos de vida de los residentes en los espacios centrales es muy rica. Se encuentran multitud de aportaciones que, en general, tratan de contrastar los estilos de vida de diferentes grupos sociales cuando conviven en los mismos espacios urbanos, por ejemplo, en estudios sobre gentrificación para explorar el eje nuevos/viejos residentes (Pablos y Sánchez-Tovar, 2003; Duque-Calvache, 2016), aunque es 
menor el número de aportaciones sobre los estilos de vida de los residentes en las cabeceras respecto a los habitantes de zonas suburbanas (Pisman et al., 2011). La literatura tiende a destacar la existencia de unos nuevos urbanitas que rechazan el modo de vida suburbano, más basado en la dispersión de los espacios de interacción social y consumo (Pablos y Susino, 2010). Buscan, por tanto, la proximidad a los lugares de trabajo, que tienden a concentrarse en las cabeceras, y evitan la dislocación entre el lugar de trabajo y residencia que caracteriza la vida en las metrópolis (Contreras, 2011). También persiguen la proximidad a las redes sociales y de afinidad, ya que la ciudad es un espacio donde encontrarse con el otro, con fines de ocio o en búsqueda de parejas sexuales (Lees et al., 2013). Por último, se busca la cercanía a los servicios personales a los que recurrir para evitar dedicar demasiado tiempo a las tareas reproductivas domésticas, y de ese modo centrarse más en el trabajo y el ocio (Schnell y Gracier, 1993).

Más allá de buscar de la proximidad en un sentido amplio, algunos también señalan la búsqueda de un ambiente cosmopolita, diverso y tolerante, que se da en las zonas más céntricas de las ciudades (Caufield, 1993). Estos sujetos neourbanitas se caracterizan por ser más participativos en el terreno del asociacionismo, así como más progresistas en términos morales y políticos (Lees et al., 2013). En general, un estilo de vida basado en la proximidad al trabajo, al ocio, a las redes sociales y a los servicios personales en aras de un desarrollo personal más individualista, frente a un modo de vida suburbano más basado en un proyecto familiar, que privilegia factores como la seguridad o la comodidad. Sin embargo, la mayoría de los estudios que analizan la preferencia por las cabeceras en conexión con los estilos de vida son cualitativos, pues no existen apenas estudios cuantitativos que tengan en cuenta estas dimensiones, más allá de la proximidad al trabajo. Se encuentran contadas excepciones que los analizan desde la perspectiva de las motivaciones de la elección residencial o los imaginarios de lo urbano (Howley, 2009; Seo, 2002).

Por último, tenemos la experiencia residencial, una variable infrecuente en los estudios de la elección residencial de las ciudades centrales, pese a que aparentemente las migraciones y los movimientos hacia las ciudades han tendido a entenderse en gran medida como movimientos de retorno, como dan a entender conceptos con los que inicialmente se empezaron a etiquetar a estos movimientos, como back to the city, en el caso Estados Unidos (Laska y Spain, 1979), o recentralización (Nel·lo, 2004), en el caso español. Aunque rara vez esta hipótesis ha llegado a contrastarse (Ley, 1996), el único estudio que hemos encontrado que aborda directamente esta cuestión (Feijten et al., 2008) afirma que el hecho de haber vivido en una ciudad incrementa la probabilidad volver a residir en un entorno urbano en el futuro: la ciudad de algún modo marca a sus habitantes.

\subsection{Diversidad territorial de la centralización: concentración, recentralización $y$ desarrollo metropolitano}

El siguiente grupo de trabajos se centra en la estructura y la dinámica de las áreas metropolitanas, más concretamente en el desarrollo por etapas de las 
mismas (Berg et al., 1982; Cheshire, 1995; Champion, 2001; Turok y Mykhnenko, 2007; Wolff, 2018). Pese a las amplias diferencias que puedan existir entre la diversidad de aportaciones, el denominador común que subyace a todas ellas consiste en entender la centralización como un flujo que predomina en determinadas etapas del proceso de desarrollo de las áreas metropolitanas, que marca, de un lado, el inicio de los procesos metropolitanos y, de otro, su etapa de madurez y complejización (Feria, 2010a). La primera fase de desarrollo de los procesos metropolitanos es la llamada de concentración urbana (Sau Reventós, 1995), la cual se da en dos etapas. Primero, la cabecera comienza a concentrar en sí una serie de actividades económicas que atraen mano de obra de unos municipios circundantes todavía rurales. En segundo lugar, esta vinculación de la población de los territorios circundantes por motivos laborales conlleva la atracción de sus residentes hacia la cabecera, la cual crece en detrimento de unas nacientes coronas metropolitanas poblacionalmente deficitarias.

Tras esta primera fase de concentración urbana, la cabecera metropolitana sufre un progresivo proceso de saturación poblacional y urbanística (LópezGay y Recaño, 2008), que conlleva el incremento de los movimientos centrífugos, con origen en las cabeceras y destino en las coronas. De este modo, entramos en la fase de suburbanización (Sau Reventós, 1995). En esta fase, la cabecera comienza poco a poco a perder población en favor de los municipios circundantes más próximos, lo que da lugar, por primera vez, a un mercado de vivienda plenamente metropolitano. Las coronas se convierten en espacios de interacción y vida cotidiana para una parte creciente de los residentes del área. Conforme se incrementan la dimensión y la madurez del área, se agudizan los movimientos de suburbanización hacia municipios hasta entonces rurales, para ampliar los límites físicos, funcionales y sociales del área metropolitana.

En una última fase, cuando las áreas alcanzan una dimensión relevante, en torno a 1.000.000 de habitantes en el caso de España, según Feria (2010b) comienza un proceso de complejización de la movilidad residencial. La estructura hasta entonces centrífuga de los flujos residenciales se rompe y surgen dos nuevos movimientos (Feria, 2010a). De un lado, los movimientos entre los municipios de la corona, los cuales suponen la emergencia de submercados de vivienda en la corona metropolitana que llegan a superar en intensidad y volumen a la suburbanización en muchas áreas (Feria, 2010a; 2015). Del otro, los municipios más integrados en la corona comienzan a perder población hacia la cabecera metropolitana, con un repunte de los movimientos centrípetos. Estos son los desplazamientos que pueden ser definidos como movimientos de recentralización.

En todo este proceso se aprecia como la centralización tiene aspectos y protagonistas diferentes según el grado de desarrollo del área. Así, en las áreas nacientes, la centralización asume la forma de la concentración, caracterizada por movimientos de ida a la ciudad, probablemente de sujetos con un perfil más heterogéneo (Torrado, 2017). Mientras tanto, en las áreas más desarrolladas, la centralización asumirá en mayor medida la forma de la recentralización, 
un movimiento que se caracteriza en mayor medida por el retorno de antiguos participantes en la suburbanización. Solo esta segunda oleada puede considerarse un movimiento de retorno, en tanto que la concentración es más bien una primera llegada a lo urbano desde espacios aún no integrados en esa dinámica.

\section{Metodología}

La fuente que utilizaremos para abordar los objetivos y contrastar las hipótesis planteadas al inicio es el Censo de Población y Vivienda de 2011. Contamos con una explotación de los microdatos que nos permite diferenciar migraciones y movilidad residencial interna en 48 áreas metropolitanas españolas, delimitadas siguiendo el criterio de Feria y Martínez (2016). Pese a la riqueza de variables con las que cuenta, es complicado acceder a las cuestiones referidas a los estilos de vida y a la experiencia residencial. Hemos decidido utilizar como variable dependiente la movilidad en el último año, la más cercana al momento censal, para reducir al mínimo el desfase que pueda existir entre las características de los individuos entre el momento del cambio y el momento censal. Por otra parte, hemos optado por operacionalizar ciertas variables disponibles como aproximaciones a los estilos de vida y la experiencia residencial. Para el análisis, se ha seleccionado una submuestra tomando solo aquellos individuos que residían en las coronas metropolitanas en 2010, es decir, trabajamos sobre la población que potencialmente podía centralizarse en el periodo de referencia. También se ha descartado de la muestra a los menores de 16 años, por dos motivos: primero, porque no tenían valores en algunas variables relevantes para el modelo (como el nivel de estudios) y, segundo, porque en la mayoría de los casos su movilidad es explicada por las características de sus familias. En la tabla 1 se recoge un análisis descriptivo de las variables empleadas.

En el análisis utilizaremos regresiones logísticas binarias para calcular la probabilidad que tienen los individuos de realizar un movimiento (centralización en nuestro caso) en función de sus características, frente al resto de opciones posibles (no moverse o moverse en la corona). La principal ventaja que suponen los modelos de regresión frente a los análisis descriptivos reside en su capacidad para cuantificar el efecto específico de cada una de las variables independientes y controlar al tiempo el resto de las variables. Es decir, que el modelo informa acerca del efecto sobre las probabilidades de un cambio en cada variable suponiendo que el resto permanecieran invariables (ceteris paribus). La variable dependiente que utilizar, dado los requerimientos del modelo propuesto, es dicotómica, es decir, asume un valor 1 (haber hecho un movimiento de centralización el año anterior a la realización del censo) o 0 (para sedentarios y participantes en otros tipos de movilidad residencial).

Para abordar el primer objetivo, hemos realizado un modelo para el conjunto de áreas españolas introduciendo las variables por pasos (bloques), para analizar mediante el cambio en pseudo-R2 y los criterios AIC y BIC la importancia de las mismas en la explicación de la centralización (Escobar et al., 2009). En cuanto al segundo objetivo, se ha reproducido el modelo completo anterior, 
Tabla 1. Variables independientes empleadas en el análisis

\begin{tabular}{|c|c|c|c|c|c|c|}
\hline \multirow[b]{2}{*}{ Variables cuantitativas } & \multicolumn{2}{|c|}{ Centralización } & \multicolumn{2}{|c|}{ Resto de alternativas } & \multicolumn{2}{|c|}{ Total } \\
\hline & Media & Desv. T. & Media & Desv. T. & Media & Desv. T. \\
\hline Edad & 38,4 & 14,7 & 47,1 & 17,9 & 47,1 & 17,9 \\
\hline Edad al cuadrado & $1.693,3$ & $1.432,6$ & $2.537,6$ & $1.824,0$ & $2.535,5$ & $1.823,6$ \\
\hline $\mathrm{N} .^{\circ}$ de tareas domésticas & 0,69 & 0,70 & 0,77 & 0,78 & 0,77 & 0,78 \\
\hline Índice de integración & 5,50 & 5,66 & 4,24 & 5,03 & 4,24 & 5,03 \\
\hline Variables cualitativas & Frec. & $\%$ & Frec. & $\%$ & Frec. & $\%$ \\
\hline \multicolumn{7}{|l|}{ Sexo } \\
\hline Hombre & 1.279 & $51 \%$ & 491.507 & $49 \%$ & 492.786 & $49 \%$ \\
\hline Mujer & 1.242 & $49 \%$ & 520.896 & $51 \%$ & 522.138 & $51 \%$ \\
\hline \multicolumn{7}{|l|}{ Estado civil } \\
\hline Soltero & 1.296 & $51 \%$ & 303.077 & $30 \%$ & 304.373 & $30 \%$ \\
\hline Casado & 770 & $31 \%$ & 588.025 & $58 \%$ & 588.795 & $58 \%$ \\
\hline Viudo & 103 & $4 \%$ & 65.916 & $7 \%$ & 66.019 & $7 \%$ \\
\hline Separado o divorciado & 352 & $14 \%$ & 55.385 & $5 \%$ & 55.737 & $5 \%$ \\
\hline \multicolumn{7}{|l|}{ Tipo de hogar } \\
\hline Unipersonal & 277 & $11 \%$ & 91.142 & $9 \%$ & 91.419 & $9 \%$ \\
\hline No familiar & 179 & $7 \%$ & 8.048 & $1 \%$ & 8.227 & $1 \%$ \\
\hline Monoparental & 202 & $8 \%$ & 81.611 & $8 \%$ & 81.813 & $8 \%$ \\
\hline Pareja sin hijos & 637 & $25 \%$ & 198.487 & $20 \%$ & 199.124 & $20 \%$ \\
\hline Pareja con hijos & 528 & $21 \%$ & 493.094 & $49 \%$ & 493.622 & $49 \%$ \\
\hline Otras familias & 698 & $28 \%$ & 140.021 & $14 \%$ & 81.813 & $8 \%$ \\
\hline \multicolumn{7}{|l|}{ Nivel de estudios } \\
\hline Primarios o inferior & 359 & $14 \%$ & 253.970 & $25 \%$ & 254.329 & $25 \%$ \\
\hline Secundarios & 563 & $22 \%$ & 302.789 & $30 \%$ & 303.352 & $30 \%$ \\
\hline FP o bachiller & 769 & $31 \%$ & 279.028 & $28 \%$ & 279.797 & $28 \%$ \\
\hline Superiores & 830 & $33 \%$ & 176.616 & $17 \%$ & 177.446 & $17 \%$ \\
\hline \multicolumn{7}{|l|}{ Condición sociolaboral } \\
\hline Profesionales & 579 & $23 \%$ & 144.693 & $14 \%$ & 145.272 & $14 \%$ \\
\hline Administrativos & 467 & $19 \%$ & 144.520 & $14 \%$ & 144.987 & $14 \%$ \\
\hline Servicios & 418 & $17 \%$ & 111.403 & $11 \%$ & 111.821 & $11 \%$ \\
\hline Operarios & 307 & $12 \%$ & 147.309 & $15 \%$ & 147.616 & $15 \%$ \\
\hline Empresarios & 145 & $6 \%$ & 76.217 & $8 \%$ & 76.362 & $8 \%$ \\
\hline Parados & 63 & $2 \%$ & 22.798 & $2 \%$ & 22.861 & $2 \%$ \\
\hline Inactivos & 510 & $20 \%$ & 354.893 & $35 \%$ & 355.403 & $35 \%$ \\
\hline Otros ocupados & 32 & $1 \%$ & 10.570 & $1 \%$ & 10.602 & $1 \%$ \\
\hline \multicolumn{7}{|l|}{ Tiene segunda vivienda } \\
\hline No & 1.644 & $65 \%$ & 755.161 & $75 \%$ & 756.805 & $75 \%$ \\
\hline Sí & 877 & $35 \%$ & 257.242 & $25 \%$ & 258.119 & $25 \%$ \\
\hline \multicolumn{7}{|l|}{ Ámbito de trabajo } \\
\hline Mismo municipio & 884 & $35 \%$ & 160.735 & $16 \%$ & 161.619 & $16 \%$ \\
\hline Otro municipio & 476 & $19 \%$ & 264.969 & $26 \%$ & 265.445 & $26 \%$ \\
\hline Fuera del área & 73 & $3 \%$ & 32.654 & $3 \%$ & 32.727 & $3 \%$ \\
\hline Varios municipios & 107 & $4 \%$ & 47.121 & $5 \%$ & 47.228 & $5 \%$ \\
\hline Mismo domicilio & 145 & $6 \%$ & 52.926 & $5 \%$ & 53.071 & $5 \%$ \\
\hline $\mathrm{Ni}$ estudia ni trabajo & 836 & $33 \%$ & 453.998 & $45 \%$ & 454.834 & $45 \%$ \\
\hline \multicolumn{7}{|l|}{ Tenencia de la vivienda } \\
\hline Propiedad & 1.352 & $54 \%$ & 867.191 & $86 \%$ & 868.543 & $86 \%$ \\
\hline Alquiler & 983 & $39 \%$ & 75.183 & $7 \%$ & 76.166 & $8 \%$ \\
\hline Cedida y otras & 186 & $7 \%$ & 70.029 & $7 \%$ & 70.215 & $7 \%$ \\
\hline \multicolumn{7}{|l|}{ Tipo de área de residencia } \\
\hline Regiones urbanas & 1.186 & $47 \%$ & 403.915 & $40 \%$ & 405.101 & $40 \%$ \\
\hline Grandes áreas & 268 & $11 \%$ & 169.524 & $17 \%$ & 169.792 & $17 \%$ \\
\hline Estándar & 464 & $18 \%$ & 190.277 & $19 \%$ & 190.741 & $19 \%$ \\
\hline Menores & 202 & $8 \%$ & 94.190 & $9 \%$ & 94.392 & $9 \%$ \\
\hline Incipientes & 114 & $5 \%$ & 48.492 & $5 \%$ & 48.606 & $5 \%$ \\
\hline Policéntricas & 287 & $11 \%$ & 106.005 & $10 \%$ & 106.292 & $10 \%$ \\
\hline Lugar de nacimiento & & & & & & \\
\hline Cabecera de la misma área & 1.024 & $41 \%$ & 288.454 & $28 \%$ & 289.478 & $29 \%$ \\
\hline Corona de la misma área & 409 & $16 \%$ & 372.417 & $37 \%$ & 372.826 & $37 \%$ \\
\hline Otra cabecera & 158 & $6 \%$ & 61.491 & $6 \%$ & 61.649 & $6 \%$ \\
\hline Otra corona & 39 & $2 \%$ & 23.420 & $2 \%$ & 23.459 & $2 \%$ \\
\hline No metropolitano & 240 & $10 \%$ & 189.925 & $19 \%$ & 190.165 & $19 \%$ \\
\hline Extranjero & 651 & $26 \%$ & 76.696 & $8 \%$ & 77.347 & $8 \%$ \\
\hline Total & 2.521 & $100 \%$ & 1.012 .403 & $100 \%$ & 1.014 .924 & $100 \%$ \\
\hline
\end{tabular}

Fuente: elaboración propia a partir del Censo de Población y Vivienda de 2011. 
con las mismas variables, pero se han seleccionado casos pertenecientes a dos tipos de áreas. Partiendo de la tipología realizada por Feria (2013) (anexo 1), de un lado, se han tomado las regiones urbanas y grandes áreas y, de otro, se han considerado las áreas menores y las incipientes (la lista de áreas incluidas en cada categoría puede verse en la tabla anexada al final). El contraste de los modelos nos permitirá saber si el efecto de las variables se modifica en función del tipo de área metropolitana, y también apreciar si la explicación alcanzada es mejor para unas u otras ciudades.

\section{Modelización de la movilidad hacia los municipios centrales}

El modelo general se ha realizado por pasos, con la introducción en cada uno de ellos de un bloque de variables. Primero, las demográficas, seguidas de las indicativas de las formas de convivencia, los dos bloques que más nos permiten aproximarnos a los cursos vitales a través del censo. Después, la posición social, operacionalizada a través del nivel de estudios y la condición sociolaboral (una combinación de la condición socioeconómica y la relación con la actividad). En cuarto lugar, las variables que hemos considerado vinculadas a los estilos de vida, dentro de las limitaciones del cuestionario censal. En quinto lugar, la experiencia residencial previa, de la cual únicamente hemos incluido el lugar de nacimiento. Y, por último, las variables territoriales: un índice de integración metropolitana del municipio ${ }^{1}$ y el tipo de área metropolitana de residencia, empleando la tipología de Feria (2013).

Una visión general de los estadísticos de ajuste de los modelos por pasos (tabla 2) permite comprobar que la introducción de los sucesivos bloques de variables mejora nuestra explicación de la centralización, como lo muestran las reducciones en los criterios AIC, BIC y el logaritmo de máxima verosimilitud, así como los incrementos en el pseudo-R2. Según estos criterios, las formas de convivencia y los estilos de vida son los bloques de variables más relevantes para la explicación del fenómeno. Aunque, en el caso de los estilos de vida, este gran incremento se explica en gran parte por haber incluido la tenencia de la vivienda, que es la variable más relevante.

En cuanto a los resultados que arroja el modelo final (tabla 3), se observa como las variables demográficas apenas son significativas, únicamente aparece la edad al cuadrado con efecto negativo, lo cual indica que la centralización es un movimiento poco frecuente en las edades más avanzadas. La forma de convivencia (en el momento del censo, por tanto, posterior al movimiento) arroja resultados más interesantes, en general, con variables significativas. Por estado civil, se observa que todas las categorías presentan propensiones bastante superiores a la centralización respecto a las personas casadas, aunque los coeficientes más grandes los encontramos en las personas que estuvieron casadas, lo cual apunta hacia la mayor vinculación entre la elección residencial

1. Calculado a partir de los flujos de entrada y salida de población residente con respecto a la cabecera, siguiendo la estrategia empleada por Susino y Barrena (2010). 
Tabla 2. Estadísticos de los modelos para la explicación de la centralización en todas las áreas españolas

\begin{tabular}{lccrrrr}
\hline $\mathbf{N = 1 . 0 1 4 . 9 2 4}$ & Demográficas & $\begin{array}{c}\text { Forma de } \\
\text { convivencia }\end{array}$ & $\begin{array}{c}\text { Posición } \\
\text { social }\end{array}$ & $\begin{array}{r}\text { Estilo } \\
\text { de vida }\end{array}$ & $\begin{array}{r}\text { Experiencia } \\
\text { residencial }\end{array}$ & Territoriales \\
\hline $\begin{array}{l}\text { Pseudo } \\
\text { R-cuadrado }\end{array}$ & 0,026 & 0,088 & 0,092 & 0,151 & 0,158 & 0,161 \\
\hline $\begin{array}{l}\text { Log. Máx. Ver. } \\
\text { Modelo vacío }\end{array}$ & -354.749 & -354.749 & -354.749 & -354.749 & -354.749 & -354.749 \\
\hline $\begin{array}{l}\text { Log. Máx. Ver. } \\
\text { Modelo final }\end{array}$ & -345.425 & -323.631 & -321.987 & -301.120 & -298.591 & -297.784 \\
\hline Sig. & 0,000 & 0,000 & 0,000 & 0,000 & 0,000 & 0,000 \\
\hline AIC & 690.858 & 647.288 & 644.013 & 602.306 & 597.258 & 595.658 \\
\hline BIC & -18.607 & -62.084 & -65.276 & -106.843 & -111.832 & -113.363 \\
\hline
\end{tabular}

Fuente: elaboración propia a partir del Censo de Población y Vivienda de 2011.

de las cabeceras y la disolución de un hogar previo, dato que casa muy bien con los que arroja el tipo de hogar. Respecto a esto último, se observa que las personas que participan en movimientos de centralización tienden a formar hogares no familiares o a convivir como pareja sin hijos, mientras que es mucho menos frecuente que se formen hogares monoparentales y parejas con hijos. Asimismo, parece que no existen diferencias significativas en la propensión a centralizarse entre los hogares unipersonales y las otras familias. Estos resultados indican que la centralización es un movimiento vinculado a formas de convivencia menos convencionales, ya sea la cohabitación con compañeros de piso o la pareja, pero rara vez implicando a los hijos. Este dato conecta directamente con la cuestión de los estilos de vida, que se analizará más adelante.

Por nivel de estudios, vemos un gradiente social claro, que muestra que la centralización es un movimiento que se vincula a aquellos individuos con estudios medios y, especialmente, superiores; no son significativas las diferencias entre aquellos que tienen estudios secundarios y primarios o inferiores. El nivel de estudios nos aproxima a la posición social y, al tiempo, constituye una medida del capital cultural. Parte de los atractivos de residir en la capital tienen que ver con la oferta cultural y de ocio (Ley, 1996), por lo que este dato nos parece coherente con la literatura. Muy relacionada con el nivel de estudios, suele encontrarse la condición sociolaboral, donde existe normalmente cierta coincidencia entre las ocupaciones más prestigiosas y mejor remuneradas y los niveles de estudios superiores. Sin embargo, en este modelo explicativo general vemos que no aparecen diferencias significativas entre las categorías profesionales más elevadas (los profesionales) y los trabajadores administrativos (categoría de referencia) y de los servicios. Este hecho apunta al carácter menos consolidado de las trayectorias profesionales de los centralizadores, que en muchas ocasiones pueden optar por situaciones de subempleo, probablemente en el sector de servicios, a la espera de encontrar un trabajo acorde a su nivel de cualificación. Sea como sea, sí que aparecen con efecto negativo las categorías de operarios y empresarios, este último grupo bastante heterogéneo, 
Tabla 3. Modelo para la explicación de la centralización en las áreas españolas

\begin{tabular}{|c|c|c|c|}
\hline & OR & & Std. Err. \\
\hline Edad & 1,006 & & 0,012 \\
\hline Edad al cuadrado & 0,999 & $\star \star \star$ & 0,000 \\
\hline Hombre (ref. = mujer) & 1,199 & * & 0,090 \\
\hline \multicolumn{4}{|l|}{ Estado civil (ref. = casados) } \\
\hline Soltero & 1,528 &  & 0,167 \\
\hline Viudo & 2,667 &  & 0,264 \\
\hline Divorciado o separado & 2,543 &  & 0,257 \\
\hline \multicolumn{4}{|l|}{ Tipo de hogar (ref. = unipersonal) } \\
\hline No familiar & 3,853 & $\star \star \star *$ & 0,777 \\
\hline Monoparental & 0,587 & $\star \star \star \star ~$ & 0,070 \\
\hline Pareja sin hijos & 1,767 & 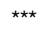 & 0,156 \\
\hline Pareja con hijos & 0,423 &  & 0,039 \\
\hline Otras familias & 1,422 & $\star \star \star \star ~$ & 0,141 \\
\hline \multicolumn{4}{|c|}{ Nivel de estudios (ref. = primarios o inferiores) } \\
\hline Secundarios & 0,980 & & 0,098 \\
\hline Bachiller o formación profesional & 1,219 & $\star \star$ & 0,081 \\
\hline Superiores & 2,189 & 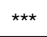 & 0,292 \\
\hline \multicolumn{4}{|c|}{ Condición sociolaboral (ref. = administrativos) } \\
\hline Profesionales & 1,091 & & 0,090 \\
\hline Servicios & 1,062 & & 0,078 \\
\hline Operarios & 0,586 & 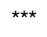 & 0,061 \\
\hline Empresarios & 0,681 & $\star \star \star *$ & 0,070 \\
\hline Parados & 0,671 & * & 0,124 \\
\hline Inactivos & 0,792 & & 0,099 \\
\hline Otros ocupados & 0,667 & & 0,180 \\
\hline N. ${ }^{\circ}$ de tareas domésticas que realiza & 0,876 & * & 0,057 \\
\hline Segunda residencia $($ ref. $=$ no) & 1,355 & 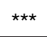 & 0,115 \\
\hline \multicolumn{4}{|c|}{ Ámbito de trabajo (ref. = municipio de residencia) } \\
\hline Otro municipio metropolitano & 0,292 & $\star \star \star *$ & 0,036 \\
\hline Fuera del área metropolitana & 0,313 & $\star \star \star \star ~$ & 0,048 \\
\hline Varios municipios & 0,510 & $\star \star \star *$ & 0,061 \\
\hline Mismo domicilio & 0,528 & 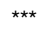 & 0,045 \\
\hline Ni estudia ni trabaja & 0,569 & 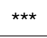 & 0,038 \\
\hline \multicolumn{4}{|l|}{ Tenencia de la vivienda (ref. = propiedad) } \\
\hline Alquiler & 4,238 & $\star \star \star *$ & 0,374 \\
\hline Cedida & 1,701 & 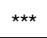 & 0,179 \\
\hline \multicolumn{4}{|c|}{ Lugar de nacimiento (ref. = cabecera de la misma área) } \\
\hline Corona de la misma área & 0,415 & *** & 0,047 \\
\hline Otra cabecera & 0,624 &  & 0,066 \\
\hline Otra corona & 0,490 & ** & 0,105 \\
\hline No metropolitano & 0,529 & 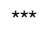 & 0,062 \\
\hline Extranjero & 0,789 & & 0,096 \\
\hline Índice de integración & 1,017 & ** & 0,005 \\
\hline \multicolumn{4}{|c|}{ Tipo de área de residencia (ref. = regiones urbanas) } \\
\hline Grandes áreas & 0,939 & & 0,119 \\
\hline Estándar & 1,397 & * & 0,225 \\
\hline Menores & 1,574 & $\star \star *$ & 0,267 \\
\hline Incipientes & 1,674 & $\star \star \star \star ~$ & 0,224 \\
\hline Policéntricas & 1,314 & & 0,281 \\
\hline Constante & 0,006 & 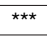 & 0,002 \\
\hline $\mathrm{N}$ & & & 1.014 .924 \\
\hline Pseudo R-cuadrado & & & 0,161 \\
\hline Log. Máx. Ver. Modelo vacío & & & -354.749 \\
\hline Log. Máx. Ver. Modelo final & & & -297.784 \\
\hline Sig. & & & 0,000 \\
\hline
\end{tabular}

${ }^{*} \mathrm{p}$-valor $<0,05 ;{ }^{\star \star} \mathrm{p}$-valor $<0,01 ;{ }^{\star \star \star} \mathrm{p}$-valor $<0,001$

Fuente: elaboración propia a partir del Censo de Población y Vivienda de 2011. 
pero que incluye a un gran número de trabajadores autónomos en situaciones muy precarias, así como a pequeños empresarios caracterizados por una fuerte vinculación territorial a su negocio (Susino et al., 2007) que los lleva, generalmente, a permanecer sedentarios.

Respecto a los estilos de vida, las variables son muy significativas. La primera, el número de tareas del hogar, muestra que, cuantas menos tareas reproductivas se realicen, mayor es la probabilidad de centralizarse, coherente con lo comentado anteriormente acerca de la ausencia de hijos. En cuanto a la disponibilidad de segunda residencia, el modelo muestra como la condición de tener segunda residencia incrementa la probabilidad de centralización. Si consideramos la segunda residencia como un bien patrimonial, constituye una variable que permite aproximarse a la posición económica. Desde el punto de vista de los estilos de vida, la segunda residencia es un indicador de un alto nivel de consumo, ya que poseer una segunda vivienda implica gastos de mantenimiento y desplazamiento.

En cuanto al lugar de trabajo o estudios, puede verse como todas las opciones posibles diferentes de trabajar en el mismo municipio (categoría de referencia) tienen una menor probabilidad de haber participado en la centralización. Este dato nos permite afirmar que los centralizadores tienden a buscarla proximidad a sus espacios de vida cotidiana, de manera que posiblemente reduzcan sus tiempos de desplazamiento diarios.

Por último, en el bloque de los estilos de vida, tenemos la tenencia de la vivienda tras el cambio de residencia. En esta variable se aprecia como la centralización se vincula a formas alternativas a la propiedad, especialmente el alquiler. Esta información es coherente con las formas de convivencia en el hogar que se vieron antes: la propiedad está mucho más vinculada a la formación de familias y a los movimientos de suburbanización. El municipio cabecera suele albergar más viviendas de alquiler, lo que hace posible combinar estas formas de hogar flexibles con una tenencia también más flexible.

En cuanto a la trayectoria residencial pasada, se aprecia como todos los sujetos presentan propensiones a centralizarse inferiores a las de los nacidos en la propia cabecera hacia la que se mueven (categoría de referencia). Por tanto, encontramos que una parte importante de los movimientos de centralización son efectivamente un retorno de antiguos habitantes. Además, si consideramos la magnitud de los coeficientes, se observa que aquellos nacidos en una cabecera metropolitana diferente son más propensos a participar en la centralización, posiblemente existe una cierta socialización en lo urbano que facilita esa elección (y viceversa, la crianza en municipios de menor tamaño disminuye la probabilidad de trasladarse a la capital). Las personas con orígenes en la misma corona son los menos propensos a ir a la cabecera, posiblemente porque conservan ciertas redes familiares o un cierto capital espacial específico en la zona (Vanzo, 1981). La mayor probabilidad de los originarios del extranjero puede tener más que ver con la disponibilidad de empleos en la cabecera, dado el componente principalmente económico de las migraciones en España. 
Por último, tenemos las variables territoriales, el índice de integración residencial del municipio de residencia hace un año y el tipo de área de residencia. El primero es significativo y con signo positivo, y muestra que cuanto más integrado esté el municipio de origen en el mercado de vivienda metropolitano, mayor es la probabilidad del sujeto de centralizarse. Dado que el índice refleja el grado de intercambio de población entre el municipio y la cabecera, los índices más altos suelen corresponder a los municipios más próximos al centro del área, y también a los que se integraron con anterioridad (lo que da pie a movimientos de retorno tras el ciclo de crianza de hijos, cuestión poco probable en los municipios integrados en la dinámica metropolitana en fechas más recientes).

El tipo de área muestra un gradiente según el desarrollo metropolitano, si bien las diferencias no son significativas entre las grandes áreas y las regiones urbanas (categoría de referencia), la propensión a la centralización es mayor en individuos residentes en áreas menos desarrolladas en términos de sus procesos metropolitanos. Lo que indica que a fecha de 2011 en España la propensión a la centralización tiene más que ver con la concentración en fases iniciales que a la recentralización de áreas maduras. Este resultado nos reafirma en la necesidad de emprender el análisis del comportamiento de los modelos cuando separamos las áreas metropolitanas según su grado de desarrollo.

\section{Los movimientos de centralización y el ciclo de expansión metropolitano}

Como se explicó en el apartado teórico, la mayor parte de los estudios sobre dinámicas urbanas se han centrado en las grandes urbes. Desde el punto de vista demográfico y simbólico, tiene sentido hacerlo, dado que son las ciudades las que albergan mayor población y las que se sitúan en la vanguardia de los cambios en las formas de movilidad y residencia. Sin embargo, nos cuestionamos si esta selección de casos no puede estar introduciendo un sesgo en la explicación de lo urbano en general y privilegiar los fenómenos y las variables cruciales en las grandes ciudades, frente a la realidad menos conocida de las ciudades pequeñas y medianas. Nuestra intención es comprobar si nuestro modelo de centralización explica mejor la decisión de los habitantes en áreas consolidadas o menos desarrolladas.

Por tanto, se ha optado por replicar el modelo de regresión logística binaria con las mismas variables (tabla 4) aplicándolo a dos submuestras de manera independiente: por una parte, reunimos los habitantes de las grandes áreas y las regiones urbanas; por otra, a los pobladores de las áreas menores y las incipientes.

Un primer vistazo a los estadísticos de ajuste de ambos modelos ya muestra como el modelo explicativo general se ajusta mucho mejor a las grandes áreas y a las regiones urbanas que a las áreas menos desarrolladas. El pseudo-R2 es el estadístico que mide la bondad de ajuste del modelo, mayor en las más desarrolladas $(0,189)$ que en las menos desarrolladas $(0,120)$, en tanto que 
Tabla 4. Modelos para la explicación de la centralización en dos tipos de áreas: regiones urbanas y grandes áreas, y menores e incipientes

\begin{tabular}{|c|c|c|c|c|c|c|}
\hline & \multicolumn{3}{|c|}{$\begin{array}{l}\text { Regiones urbanas } \\
\text { y grandes áreas }\end{array}$} & \multicolumn{3}{|c|}{$\begin{array}{l}\text { Áreas menores } \\
\text { e incipientes }\end{array}$} \\
\hline & OR & & Std. Err. & OR & & Std. Err. \\
\hline Edad & 1,018 & & 0,015 & 0,980 & & 0,037 \\
\hline Edad al cuadrado & 0,999 & ** & 0,000 & 0,999 & & 0,000 \\
\hline Hombre (ref. = mujer) & 1,052 & & 0,076 & 1,308 & & 0,200 \\
\hline \multicolumn{7}{|l|}{ Estado civil (ref. = casados) } \\
\hline Soltero & 1,982 & 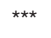 & 0,189 & 1,408 & & 0,322 \\
\hline Viudo & 2,726 & $\star \star \star \star ~$ & 0,507 & 3,706 & ** & 1,403 \\
\hline Divorciado o separado & 3,046 &  & 0,334 & 2,159 & ** & 0,575 \\
\hline \multicolumn{7}{|l|}{ Tipo de hogar (ref. = unipersonal) } \\
\hline No familiar & 4,901 & 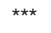 & 0,707 & 1,073 & & 0,531 \\
\hline Monoparental & 0,535 & $* \star *$ & 0,078 & 0,551 & * & 0,164 \\
\hline Pareja sin hijos & 1,791 & $* \star *$ & 0,216 & 1,954 & * & 0,533 \\
\hline Pareja con hijos & 0,356 & 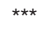 & 0,046 & 0,373 & 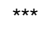 & 0,095 \\
\hline Otras familias & 1,440 & $\star \star \star ~$ & 0,172 & 1,188 & & 0,294 \\
\hline \multicolumn{7}{|c|}{ Nivel de estudios (ref. $=$ primarios o inferiores) } \\
\hline Secundarios & 1,080 & & 0,137 & 0,957 & & 0,226 \\
\hline Bachiller o formación profesional & 1,269 & * & 0,153 & 1,380 & & 0,322 \\
\hline Superiores & 2,731 & $\star \star \star * *$ & 0,332 & 1,574 & & 0,434 \\
\hline \multicolumn{7}{|c|}{ Condición sociolaboral (ref. = administrativos) } \\
\hline Profesionales & 1,215 & * & 0,119 & 1,017 & & 0,276 \\
\hline Servicios & 1,124 & & 0,125 & 1,016 & & 0,241 \\
\hline Operarios & 0,663 & ** & 0,084 & 0,509 & * & 0,133 \\
\hline Empresarios & 0,752 & & 0,116 & 0,685 & & 0,200 \\
\hline Parados & 0,783 & & 0,175 & 0,361 & & 0,216 \\
\hline Inactivos & 0,839 & & 0,104 & 0,730 & & 0,207 \\
\hline Otros ocupados & 0,957 & & 0,250 & 0,903 & & 0,471 \\
\hline Tareas domésticas que realiza $\left(\mathrm{n} .^{\circ}\right)$ & 0,787 & $* \star \star \star *$ & 0,036 & 1,020 & & 0,089 \\
\hline Segunda residencia (ref. = no) & 1,354 & $* \star *$ & 0,093 & 1,353 & & 0,214 \\
\hline \multicolumn{7}{|c|}{ Ámbito de trabajo (ref. = municipio de residencia) } \\
\hline Otro municipio metropolitano & 0,245 & $* \star *$ & 0,022 & 0,468 & ** & 0,111 \\
\hline Fuera del área metropolitana & 0,259 & $\star \star \star \star ~$ & 0,065 & 0,536 & * & 0,137 \\
\hline Varios municipios & 0,530 & $\star \star$ & 0,113 & 0,636 & & 0,245 \\
\hline Mismo domicilio & 0,513 & $* \star \star *$ & 0,070 & 0,646 & & 0,194 \\
\hline Ni estudia ni trabaja & 0,562 &  & 0,047 & 0,833 & & 0,149 \\
\hline \multicolumn{7}{|c|}{ Tenencia de la vivienda (ref. = propiedad) } \\
\hline Alquiler & 3,905 & $\star \star \star \star ~$ & 0,377 & 4,948 & $\star \star \star \star ~$ & 1,144 \\
\hline Cedida & 1,981 & $\star \star \star * *$ & 0,246 & 2,080 & ** & 0,468 \\
\hline \multicolumn{7}{|c|}{ Lugar de nacimiento (ref. = cabecera de la misma área) } \\
\hline Corona de la misma área & 0,451 & $* \star \star *$ & 0,045 & 0,376 & 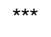 & 0,083 \\
\hline Otra cabecera & 0,686 & $\star \star$ & 0,096 & 0,423 & $\star \star$ & 0,113 \\
\hline Otra corona & 0,551 & * & 0,137 & 0,264 & * & 0,163 \\
\hline No metropolitano & 0,554 & $* \star *$ & 0,068 & 0,688 & & 0,171 \\
\hline Extranjero & 1,056 & & 0,108 & 0,444 & 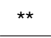 & 0,109 \\
\hline Índice de integración & 1,014 & $\star \star$ & 0,005 & 1,026 & & 0,027 \\
\hline Constante & 0,004 & 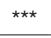 & 0,001 & 0,017 & $\star \star \star \star ~$ & 0,016 \\
\hline $\mathrm{N}$ & & & 574.893 & & & 142.998 \\
\hline Pseudo R-cuadrado & & & 0,197 & & & 0,130 \\
\hline Log. Máx. Ver. Modelo vacío & & & 198.215 & & & -40.641 \\
\hline Log. Máx. Ver. Modelo final & & & 159.163 & & & -35.374 \\
\hline Sig. & & & 0,000 & & & 0,000 \\
\hline
\end{tabular}

${ }^{*} \mathrm{p}$-valor $<0,05 ;{ }^{* *} \mathrm{p}$-valor $<0,01 ;{ }^{* * *} \mathrm{p}$-valor $<0,001$

Fuente: elaboración propia a partir del Censo de Población y Vivienda de 2011. 
el modelo general, al reunir ambas, tenía un valor intermedio $(0,153)$. Este dato revela que, al reunir los datos sin tener en cuenta el tipo de área, estamos mezclando realidades diferentes y hasta cierto punto opuestas, lo que enturbia el modelo conjunto.

Si analizamos la dirección y la significatividad de las variables en ambos modelos (cuadro 5), se observa que en el caso de las áreas más desarrolladas estas operan de manera casi calcada al modelo general descrito, con contadas excepciones, mientras que en el caso de las áreas nacientes su funcionamiento es bastante diferente. Este dato es hasta cierto punto esperable, puesto que numéricamente son mucho más abundantes en la muestra los residentes en las grandes urbes que en las menores, por lo que su peso en las tendencias agregadas es también mayor.

En el caso de las variables demográficas, se aprecia que en las áreas nacientes ninguna es significativa, mientras que en las más consolidadas lo es la edad al cuadrado, como lo era en el modelo general. En el caso de las formas de convivencia, se observan diferencias más relevantes. Si bien en las principales áreas todas las categorías de estado civil son significativas y presentan una propensión positiva, en las áreas nacientes la categoría de solteros pierde significatividad, es un movimiento más vinculado a cambios posteriores en términos de los cursos vitales de sus protagonistas que a la emancipación residencial. La convivencia en hogares no familiares es muy relevante en grandes urbes, y no significativa en las pequeñas, algo que casa bien con la tesis de su menor vinculación a procesos de emancipación residencial. Además, este dato está vinculado a los mayores precios de la vivienda en las ciudades más pobladas, que impulsa a compartir gastos, y también posiblemente a la presencia de inmigrantes, más propensos a compartir vivienda con personas no emparentadas, y también más presentes en las grandes ciudades. En áreas menores, la clave para la centralización es la presencia de descendencia en el hogar.

Respecto a las variables indicativas de la posición social, vemos que en las principales áreas la condición de tener estudios superiores y de pertenecer a los estratos mejor situados en la estructura social — los profesionales-incrementa la probabilidad de moverse hacia las ciudades, una pauta esta última que no aparecía en el modelo general y que vincula de manera más contundente los procesos de recentralización a las clases medias altas. Mientras, en las áreas menores e incipientes, estas variables pierden su significatividad, más allá del efecto negativo de pertenecer a las categorías de clase trabajador tradicional (operarios), por lo que puede afirmarse que en ellas la centralización es un movimiento socialmente más heterogéneo que en las áreas más desarrolladas, donde se vincula principalmente a los sujetos mejor posicionados en la estructura social. Esto parece confirmarse si consideramos la disponibilidad de segunda residencia como un elemento de distinción social. Así, se aprecia que en las áreas más consolidadas tener una segunda residencia incrementa la propensión a la centralización, mientras en las áreas nacientes este factor no es significativo. De nuevo, los niveles de precios pueden ser un elemento clave para entender estas diferencias en los comportamientos residenciales. 
En el bloque de estilos de vida, se encuentran importantes variaciones. En general, son mucho más significativas en las grandes áreas, lo que nos indica que las explicaciones basadas en este factor son mucho más adecuadas para entender la recentralización de áreas maduras que para analizar el proceso de concentración en fases tempranas del ciclo metropolitano. La única variable que funciona mejor en las ciudades menores es la tenencia, que es precisamente un elemento mucho más tangible y no únicamente vinculado a las maneras de vivir, sino también a las condiciones materiales de existencia.

En cuanto a la trayectoria residencial previa, en este bloque encontramos las mayores diferencias en los valores de los coeficientes entre ciudades grandes y menores. Solo en las grandes áreas los extranjeros y los que nacieron en otra cabecera se centralizan en proporción cercana a los que nacieron en la propia cabecera. En las áreas de menor tamaño, tener orígenes en la corona reduce la probabilidad; sin embargo, los que nacieron en espacios no metropolitanos no se diferencian significativamente de los nacidos en la misma corona, lo que refuerza la idea de que en estas ciudades hay un patrón de concentración sucesivo. Personas procedentes de entornos rurales se van acercando progresivamente a la capital, aunque primero pasan por la corona metropolitana, lo que culturalmente supone una transición más suave en cuanto a modos de vida.

Por último, se aprecia que el efecto del índice de integración es significativo y positivo en las grandes áreas y las regiones urbanas, pero no lo es en el caso de las áreas menores e incipientes. Para que se produzcan diferencias relevantes en las coronas, con espacios más y menos involucrados en la dinámica, es necesaria cierta madurez en el desarrollo. También apuntamos anteriormente que la integración tiene que ver con las distancias, por lo que es lógico que solo aparezca como elemento explicativo donde las distancias son mayores.

\section{Conclusiones}

La mayor parte de los trabajos que han abordado la cuestión de la centralización, o al menos se han aproximado a ella a través del estudio de los llamados nuevos residentes urbanos, han tendido a caracterizar a los individuos que eligen las ciudades como espacio residencial como sujetos que conviven en hogares no tradicionales (Buzar et al., 2005; Buzar et al., 2007), que, o bien han sufrido cambios en sus cursos vitales posteriores al nacimiento de los hijos, o bien anteriores (Marois y Bélanger, 2013). En general, son sujetos de un perfil social elevado (Ley, 1996; Duque-Calvache, 2015), que regresan a su ciudad de origen o a una similar (Feijten et al., 2008), y que buscan la consecución de unos estilos de vida urbanos (Pablos y Sánchez-Tovar, 2003) basados en la proximidad de los espacios de vida, así como la externalización de una serie de tareas reproductivas, dada la importancia central que para ellos tienen sus carreras profesionales y sus relaciones sociales (Schnell y Gracier, 1993).

Nuestro primer modelo nos ha servido para contrastar y medir la influencia de dichas variables de tipo individual en la conducta residencial relativa a los movimientos de centralización en España. En ese sentido, supone una 
confirmación de la pertinencia de las explicaciones, si bien el poder predictivo del modelo se ve lastrado por el tipo de datos que proporciona el censo. Una fuente de tipo longitudinal, dirigida a la medición de aspectos clave para la conducta residencial, podría alcanzar niveles de explicación mucho más elevados. Desafortunadamente, no contamos con una fuente de ese tipo. Al tiempo, nuestra hipótesis era que parte de la explicación de este cambio no tiene que ver con estos factores micro, sino con variables agregadas relacionadas con el tamaño, el tipo y el grado de desarrollo del área metropolitana. Los resultados confirman la relevancia de estas cuestiones agregadas, incluso cuando controlamos los factores micro, lo que corrobora que no se trata de un mero efecto de composición, coherentemente con lo hallado en trabajos anteriores (Duque-Calvache et al., 2017).

Nuestro segundo objetivo era analizar el efecto del desarrollo metropolitano a través de la introducción del tipo de área metropolitana no como variable explicativa, sino como criterio de muestreo. Entre los resultados de este ejercicio, se encuentra comprobar que la centralización en las áreas de menor entidad requiere de una explicación diferente, ya que el modelo general propuesto no se ajusta tan bien a las mismas como a las grandes áreas y las regiones urbanas, e incluso es diferente el efecto y la significatividad de las variables explicativas del fenómeno en unas áreas y otras. Así lo veíamos en el caso de las formas de convivencia, el ámbito de trabajo o la experiencia residencial, por poner algunos ejemplos. Esto confirma lo apuntado en trabajos que señalan que en este tipo de urbes los movimientos centrípetos asumen la forma de la concentración en lugar de la recentralización, y tienen protagonistas también diferentes (Torrado, 2017).

El renovado atractivo residencial y económico de los municipios centrales está detrás de muchos de los procesos de cambio urbano del presente, tales como la gentrificación o la renovación urbana, que son manifestaciones concretas geográfica y socialmente de este proceso más general. En ese sentido, este trabajo aporta un marco de entendimiento más amplio que el habitualmente empleado al estudiar tales temas, mucho más volcado en el choque entre nuevos y viejos vecinos y los procesos de renovación y reemplazo. Por otra parte, nuestros resultados ponen de manifiesto la necesidad de analizar otras realidades urbanas menores que han tendido, o bien a ser omitidas, o bien a tratar de extrapolar a las mismas las explicaciones que operan en las grandes urbes. Práctica común que puede introducir sesgos y poner de manifiesto la necesidad de realizar aportaciones y explicaciones específicas para estas ciudades pequeñas y medianas.

\section{Referencias bibliográficas}

Andújar, Andrea; Feria, José María; Iglesias, Ricardo y Granados, Miguel Ángel (2015). Áreas metropolitanas andaluzas. Caracteristicas y condiciones del parque de viviendas. Sevilla: Consejería de Fomento de la Junta de Andalucía.

Berg, Leo van den; Drewett, Roy; KlaAsen, Leo; Rossi, Angelo y Vijverberg, Cornells H. T. (1982). Urban Europe: a study of growth and decline. Oxford: Pergamon Press. 
Buzar, Stefan; Ogden, Philip E. y Hall, Ray (2005). «Households matter: the quiet demography of urban transformation». Progress in Human Geography, 29 (4), 413-436. <https://doi.org/10.1191/0309132505ph558oa>

- (2007). "Beyond gentrification: The demographic reurbanisation of Bologna». Environment and Planning A, 39 (1), 64-85. <https://doi.org/10.1068/a39109>

Buzar, Stefan; Ogden, Philip E.; Hall, Ray; Haase, Annegret; Kabisch, Sigrun y STEInfüHrer, Annett (2007). «Splintering Urban Populations: Emergent Landcapes of Reurbanisation in Four European Cities». Urban Studies, 44 (4), 651-677. <https://doi.org/10.1080/00420980601185544>

Caulfield, Jon (1993). City form and everyday life: Toronto's gentrification and critical social practice. Toronto: Toronto University Press.

Champion, Tony (2001). «Urbanization, Suburbanization, Counterurbanization and Reurbanization». En: Paddison, R. (ed.). Handbook of Urban Studies, 143-161. Londres: SAGE Publications Ltd.

Cheshire, Paul (1995). "A New Phase of Urban Development in Western Europe? The Evidence for the 1980s». Urban Studies, 32 (7), 1.045-1.063.

Contreras, Yasna (2011). «La recuperación urbana y residencial del centro de Santiago: Nuevos habitantes, cambios socioespaciales significativos». Eure, 37 (562).

Coulter, Rory; Ham, Maarten van y Findlay, Allan M. (2016). "Re-thinking residential mobility». Progress in Human Geography, 40 (3), 352-374. <https://doi.org/10.1177/0309132515575417>

Criekingen, Mathieu van (2010). "Gentrifying the Re-urbanisation Debate”, Not Vice Versa: The Uneven Socio-spatial Implications of Changing Transitions to Adulthood in Brussels». Population, Space and Place, 16, 381-394. $<$ https://doi.org/10.1002/psp.582>

Duque-Calvache, Ricardo (2015). Áreas metropolitanas andaluzas. La movilidad residencial y su relación con la vivienda. Sevilla: Consejería de Fomento de la Junta de Andalucía.

- (2016). Procesos de gentrificación en cascos antiguos: el Albaicín de Granada. Madrid: Centro de Investigaciones Sociológicas.

Duque-Calvache, Ricardo; Torrado, José Manuel y Fuster, Nayla (2017). «La importancia de los factores espaciales y contextuales en la movilidad residencial». Papers, 102 (4), 607-635. <http://dx.doi.org/10.5565/rev/papers.2415>

Escobar, Modesto; Fernández, Enrique y Bernardi, Fabrizio (2009). Análisis de datos con Stata. Madrid: Centro de Investigaciones Sociológicas.

Feijten, Peteke y Ham, Maarten van (2007). «Residential mobility and migration of the divorced and separated». Demographic Research, 17, 623-654. <https://doi.org/10.4054/DemRes.2007.17.21>

Feijten, Peteke; Hooimeijer, Pieter y Mulder, Clara H. (2008). «Residential experience and residential environment choice over the life-course». Urban Studies, 45 (1), 141-162. <https://doi.org/10.1177/0042098007085105>

Feria, José María (2010a). «Ciudad y Territorio: Nuevas dinámicas espaciales». En: Pujadas, I. (ed.). Población y espacios urbanos, 13-52. Barcelona: Departament de Geografia Humana de la UB y Grupo de Población de la AGE. 
- (2010b). «La delimitación y organización espacial de las áreas metropolitanas españolas: una perspectiva desde la movilidad residencia-trabajo». Ciudad y Territorio, 42 (164), 189-210.

- (2013). «Towards a Taxonomy of Spanish Metropolitan Areas». Boletín de la Asociación de Geógrafos Españoles, 63, 349-378.

- (2015). «Los modelos de organización y dinámicas espaciales metropolitanas en Andalucía». Cuadernos Geográficos, 54 (2), 196-219.

Feria, José María y Andújar, Andrea (2015). «Movilidad residencial metropolitana y crisis inmobiliaria». Anales de Geografía, 35 (1), 129-140.

Feria, José María y Martínez, Lucas (2016). «La definición y delimitación del sistema metropolitano español. Permanencias y cambios entre 2001 y 2011». Ciudady Territorio, 48 (187), 9-24.

Ford, Tania y Champion, Tony (2000). "Who moves into, out of and within London? An analysis based on the 1991 Census 2\% sample of anonymised records». Area, 32 (3), 259-270. <https://doi.org/10.1111/j.1475-4762.2000.tb00139.x>

Galiana, Luis y Vinuesa, Julio (2012). «Descentralización y recentralización en espacios metropolitanos maduros: el caso de Madrid». En: Palacios, A. y Porras, D. (eds.). Metrópolis. Dinámicas Urbanas, 23-48. Madrid: Universidad Autónoma de Madrid y Universidad Nacional de Luján.

Gober, Patricia y Behr, Michelle (1982). «Central Cities and Suburbs as Distinct Place Types: Myth or Fact?». Economic Geography, 58 (4), 371-385.

Howley, Peter (2009). "Attitudes towards compact city living: Towards a greater understanding of residential behaviour». Land Use Policy, 26 (3), 792-798. <https://doi.org/10.1016/j.landusepol.2008.10.004>

Laska, Shirley y Spain, Daphne (1979). «Urban Policy and Planning in the Wake of Gentrification Anticipating Renovators Demands». Journal of the American Planning Association, 45 (4), 523-531.

Lees, Loretta; Slater, Tom y Wyly, Edwin K. (2013). Gentrification. Nueva York: Routledge.

Ley, David (1996). The New Middle Class and the Remaking of the Central City. Toronto: Oxford Geographical and Environmental Studies Series.

López-Gay, Antonio (2014). «Population growth and re-urbanization in Spanish inner cities: The role of internal migration and residential mobility». Revue Quetelet / Quetelet Journal, 1 (2), 67-92. <https://doi.org/10.14428/rqj2014.02.01.03>

- (2017). «Hacia un patrón territorial complejo de la movilidad residencial. El caso de la Región Metropolitana de Barcelona». Papers, 102 (4), 793-823. $<$ https://doi.org/10.5565/rev/papers.2420>

López-GAY, Antonio y RECAÑo, Joaquín (2008). «La renovación sociodemográfica de un centro urbano maduro: perfiles migratorios y filtros residenciales en la ciudad de Barcelona». Scripta Nova, 12 (126).

Mahmud, Shahril Anwar; Abdullah Sani, Ahmad y Aminatuzuhariah Megat, Abdullah (2012). "Lifestyle Orientation and the Residential Environment: An Exploratory Review». Procedia - Social and Behavioral Sciences, 49, 304-309. <https://doi.org/10.1016/j.sbspro.2012.07.028>

Marois, Guillaume y BéLANGER, Alain (2013). «De la banlieue à la ville centre: déterminants de la mobilité résidentielle des banlieusards de Montréal». Canadian Journal of Urban Research, 22 (2), 45-68. 
NeL.LO, Oriol (2004). "¿Cambio de siglo, cambio de ciclo? Las grandes ciudades españolas en el umbral del siglo xxI». Ciudad y Territorio (141-142), 523-542.

Nelson, Kathryn P. y Edwards, John G. (1993). «Intra-urban mobility and location choice in the 1980s». En: Kingsley, G. T. y Turner, M. A. (eds.). Housing markets and residential mobility, 53-95. Washington, DC: Urban Institute Press.

Nguyen, Scott (2006). The Central City: Why the Comeback? Boston: Massachusetts Institute of Technology.

Pablos, Juan Carlos de y Sánchez-Tovar, Ligia (2003). «Estilos de vida y revitalización del espacio urbano». Papers, 71, 11-31. <http://dx.doi.org/10.5565/rev/papers/v71n0.1148>

Pablos, Juan Carlos de y Susino, Joaquín (2010). «Vida urbana: entre la desigualdad social y los espacios del habitar». Anduli, 9, 119-142.

Pisman, Ann; Allaert, Georges, y Lombaerde, Piet (2011). «Urban and suburban lifestyles and residential preferences in a highly urbanized society experiences from a case study in Ghent (Flanders, Belgium)». Belgeo (1-2), 89-104. <https://doi.org/10.4000/belgeo.6394>

Pujadas, Isabel; Bayona, Jordi y Gil-Alonso, Fernando (2012). «Las Grandes Metrópolis Españolas en la Encrucijada. Crecimiento, Migración y Suburbanización en la Última Década». Contexto. Revista de la Facultad de Arquitectura de la Universidad Autónoma de Nuevo León (México), 7 (6), 11-32.

Sanchez, Thomas W. y Dawkins, Casey J. (2001). "Distinguishing city and suburban movers: Evidence from the American housing survey». Housing Policy Debate, 12 (3), 607-631. <https://doi.org/10.1080/10511482.2001.9521420>

SAU Reventós, Elisabet (1995). «El creixement del sistema urbà de Catalunya (19501991). De la concentració a la desconcentració metropolitana?». Documents d'Anàlisi Geogràfica, 27, 97-113.

Schnell, Izhak y Gracier, Iris (1993). «Causes of In-migration to Tel Aviv Inner City». Urban Studies, 30 (7). <https://doi.org/10.1080/00420989320081121>

SEO, Joon-Kyo (2002). "Re-urbanisation in regenerated areas of Manchester and Glasgow: New residents and the problems of sustainability». Cities, 19 (2), 113-121. <https://doi.org/10.1016/S0264-2751(02)00006-9>

South, Scott J. y Crowder, Kyle D. (1997). «Residential Mobility Between Cities and Suburbs: Race, Suburbanization, and Back-to-the-city Moves». Demography, 34 (4), 525-538.

Storper, Michael y Manville, Michael (2006). «Behaviour, Preferences and Cities: Urban Theory and Urban Resurgence». Urban Studies, 43 (1.247). <https://doi.org/10.1080/00420980600775642>

Susino, Joaquín y Barrena, Eva (2010). «Propuesta de delimitación de las áreas metropolitanas andaluzas como espacios de vida». En: Delgado, C. (ed.). Actas del X Coloquio y Jornadas de Campo de Geografía Urbana. Espacios y paisajes urbanos: reflexionar sobre su presente para proyectar su futuro, 533-543. Universidad de Cantabria, Santander.

Susino, Joaquín; Casado, José Manuel y Feria, José María (2007). «Transformaciones sociales y territoriales en el incremento de la movilidad por razón de trabajo en Andalucía». Cuadernos de Geografía, 81, 71-91. 
Susino, Joaquín y Duque-Calvache, Ricardo (2012). «Veinte años de suburbanización en España, 1981-2001: el perfil de sus protagonistas». Documents d'Anàlisi Geográfica, 59 (2), 265-290. <https://doi.org/10.5565/rev/dag.31>

Susino, Joaquín y Palomares-Linares, Isabel (2013). «La movilidad residencial en el área metropolitana de Granada». En: Camacho, J. A. y Jiménez, Y. (eds.). Desarrollo Regional Sostenible en tiempos de crisis, 2, 345-364. Granada: Universidad de Granada.

Torrado, José Manuel (2017). «Diversidad de dinámicas de movilidad residencial hacia las cabeceras metropolitanas andaluzas». Revista de Estudios Andaluces, 34, 502-528.

- (2018). «¿Seleccionan las ciudades a su población? Tendencias de selectividad residencial en las cabeceras metropolitanas andaluzas». Cuadernos Geográficos, 57 (2), 211-236.

Turcotte, Martin y Vézina, Mireille (2010). «Migration entre municipalité centrale et municipalités avoisinantes à Toronto, Montréal et Vancouver». Tendances Sociales Canadiennes, 90.

Turok, Ivan y Myknnenko, Vlad (2007). «The trajectories of European cities, 19602005». Cities, 24 (3), 165-182. <https://doi.org/10.1016/j.cities.2007.01.007>

Ullán de la Rosa, Francisco Javier (2014). Sociología Urbana: De Marx y Engels a los teóricos posmodernos. Madrid: Centro de Investigaciones Sociológicas.

VAnzo, Julie da (1981). «Repeat migration, information costs, and location-specific capital». Population and Environment, 4 (1), 45-73.

WolfF, Manuel (2018). «Understanding the role of centralization processes for cities - Evidence from a spatial perspective of urban Europe 1990-2010». Cities. <https://doi.org/10.1016/j.cities.2017.01.009>

Anexo. Clasificación de áreas siguiendo la tipología de Feria (2013)

\begin{tabular}{|c|c|c|c|c|c|}
\hline $\begin{array}{l}\text { Regiones } \\
\text { urbanas }\end{array}$ & $\begin{array}{l}\text { Grandes } \\
\text { áreas }\end{array}$ & Estándar & $\begin{array}{l}\text { Áreas } \\
\text { menores }\end{array}$ & $\begin{array}{l}\text { Áreas } \\
\text { incipientes }\end{array}$ & Policéntricas \\
\hline $\begin{array}{l}\text { Barcelona, } \\
\text { Madrid }\end{array}$ & $\begin{array}{l}\text { Valencia, } \\
\text { Sevilla, } \\
\text { Bilbao }\end{array}$ & $\begin{array}{l}\text { La Coruña, Castellón, } \\
\text { San Sebastián, } \\
\text { Granada, Murcia, } \\
\text { Palma de Mallorca, } \\
\text { Las Palmas de } \\
\text { Gran Canaria, } \\
\text { Pamplona, Santa } \\
\text { Cruz de Tenerife, } \\
\text { Santander, Tarragona, } \\
\text { Valladolid, Zaragoza }\end{array}$ & $\begin{array}{l}\text { Algeciras, } \\
\text { Ferrol, Gerona, } \\
\text { Huelva, León, } \\
\text { Lérida, Logroño, } \\
\text { Orense, Salamanca, } \\
\text { Santiago de } \\
\text { Compostela, Toledo }\end{array}$ & $\begin{array}{l}\text { Albacete, } \\
\text { Badajoz, } \\
\text { Burgos, } \\
\text { Cartagena, } \\
\text { Córdoba, Jaén, } \\
\text { Vitoria, Arona, } \\
\text { Benidorm }\end{array}$ & $\begin{array}{l}\text { Almería- } \\
\text { El Ejido, Avilés- } \\
\text { Gijón-Oviedo, } \\
\text { Cádiz-Jerez, } \\
\text { Elche-Alicante, } \\
\text { Málaga-Marbella, } \\
\text { Pontevedra-Vigo }\end{array}$ \\
\hline
\end{tabular}

